\title{
Driving the Knowledge Economy: Explaining the Impact of Regional Innovation Capacity on Economic Performance
}

\author{
Benjamin J.K. Yeo \\ E-mail: benjkyeo@gmail.com
}

\begin{abstract}
The knowledge economy represents an intangible economic configuration whereby knowledge is valued as a key factor in production. Economic growth in leading world economies is increasingly based on knowledge, in addition to tangible assets such as capital and labor. Knowledge work involves creation, and can therefore be operationalized by innovation for empirical analysis. Under this definition, this study looks at the innovation capacities across all metropolitan regions in the U.S., and the extent to which they determine economic growth in these regions. Using industry data on U.S. metropolitan regions from 1988 to 2007, the research findings show that the impact of innovation capacity on economic growth has significantly increased after the dot com era. However, the magnitude of increment was small. This can be explained by the wide variations in the U.S. in industry bases, and their regionspecific contextual factors. To explain these findings, the study concludes with a literature review on a contextual approach to study the economic impact of innovation capacity on a region's economic performance. The researcher proposes taking a more focused and less aggregated approach to study and compare regions, so as to account for various contextual factors.
\end{abstract}

Keywords: Innovation Capacity, Knowledge Economy, Economic Growth

\section{SHIFTING TOWARDS THE KNOWLEDGE ECONOMY}

In the 1970s, advanced industrial nations experienced a fundamental economic transition from a manufacturing base to a service-based orientation, leading to the post-industrial economy (Powell \& Snellman, 2004; Bell, 1973; Block, 1990). Underlying this economic change is the increased industrial dependency on information and knowledge for production. Powell and Snellman (2004) cited an example of websites like Amazon.com that engage in electronic commerce include 
value-added services on their websites that monitor tastes to make recommendations to consumers (Powell \& Snellman, 2004). These services are provided through the use of highly sophisticated information technologies and, more importantly, application of the knowledge of the business to customer relationship management.

The most technologically advanced economies are knowledge-based countries with an evolutionary economic orientation: In these countries, knowledge is a crucial factor, along with land, tools, and labor, in determining the standard of living (World Bank, 1999). In the knowledge economy, the leverage of information and communication technologies can potentially increase the return on investments over time. This explains at least partially why sustainability can be achieved by developed countries while developing countries cannot despite their large labor pools and capital (Romer, 1990; Romer, 1986). Under this new paradigm, labor and capital are still endogenous factors of production. However, knowledge, productivity, education, and intellectual capital, although significant factors, are conceptualized as exogenous factors that are not within the economic system (Ernst and Young, 1999). Here, labor encompasses physical labor and the ideas that reside within human labor. Therefore, increased investments in human capital, knowledge, and fixed capital play important endogenous roles in economic development (Hulten, 2001).

In this paradigm, ideas and creativity are determinants of economic growth because they integrate concepts of labor and capital. Therefore, ideas and creativity increase the output, and hence productivity, of goods produced through labor and capital. In this economy, the production and consumption of information goods and services are not as limited by labor and capital as in an industrial economy because of the possibility of replication (Mosco, 1989).

Therefore, it follows that increasing rather than diminishing returns on technological investments can be achieved with the introduction and integration of new technologies (Ernst and Young, 1999). Technology then, including its knowledge base, is an inherent component of an economic system. Knowledge therefore, ascends to become a third endogenous factor of production in the advanced economies of the world (Romer, 1990; Romer, 1986). The knowledge economy therefore, is made up of industries engaged in ideas and creativity, that is, innovation. 


\section{INNOVATION AND THE KNOWLEDGE ECONOMY}

The concept of innovation as applied to a segment of the economy defines knowledge work. Knowledge work can occur in all professions and all segments of the economy. It is important to acknowledge that the scope of the knowledge economy is not reduced to just professionals and high-tech businesses. As a primary source of wealth creation (Kim \& Mauborgne, 1999), innovation can be defined as the creation and use of a new product, procedure, or service. Among activities included in the definition of innovation are scientific, technical, and market research; product, process, or service development; and manufacturing and marketing in order to support diffusion and application of invention (U.S. Congress, Office of Technology Assessment, 1995). Since innovation can be applied to any industry, knowledge industries are not restricted to technology-based industries per se.

According to the National Science Foundation (NSF) of America, innovation is measured by the employment of scientists and technicians because they reflect the human resource component of innovation (National Science Foundation, 2007). The role of human capital has been acknowledged as an integral part of regional development and the geographic concentration of innovation (Ullman, 1958). These workers contribute ideas and play key roles in the production and diffusion of innovation. Knowledge workers who engage in research and development, that is, innovation.

Florida (2002) found that metropolitan areas have abundant work and lifestyle opportunities for the creative class of people. As such, a wide range of economic production activities occur in metropolitan regions (Florida, 2002). Human creativity and technological innovation experience advantages in these metropolitan regions. The high concentration of these economic production activities leads to new production processes (Desrochers, 2001), thus yielding the innovation process. This process, when continued, then becomes a sustainable process, and thus constitutes the sustainable knowledge economy, where ideas and innovation are valued.

According to Gault (2005), established indicators of knowledge creation, such as research and development activities and intellectual property commercialization, are static indicators that cannot capture the dynamism involved in the knowledge economy (Gault, 2005). As such, these measures may not be suitable in defining knowledge work explicitly for empirical research. Although they capture the concept of innovation, they only reflect the output of innovation, which is creation based on knowledge. 
Hence, the importance of learning cannot be ignored. It forms the basis for innovation, and hence knowledge creation. Research and development activities (at the macro level) and individual apprenticeship (at the individual level) exemplify this process by aiming at innovation. Technological innovation creates benefits that reduce costs. A corresponding value innovation is essential to realize the potential of the technological innovation. It must be noted, however, that both technological and value innovation are tightly inter-related. Value innovation involves leveraging technological innovation for economic benefits (Dillon, Lee \& Matheson, 2005). This continued process of value innovation based on continued learning then becomes the key to sustainability.

The advent of information technologies also fuels this process. These interactions create new opportunities for continuous learning. This process becomes crucial to the long-term sustainability of the knowledge economy (Glaeser, 1999). In addition, metropolitan regions are also inhabited with knowledge assets such as tertiary educational institutions, research institutes, as well as technology transfer centers.

DeVol (2002) argued that a region's technology dynamism and outcomes are essential to a region's economic well-being (DeVol, 2002). Human capital is an essential component that can be leveraged to promote economic development in an intangible asset-based economy ( $\mathrm{DeVol}, 2002)$. He continued to argue therefore, that economic growth depends on investments in education, new work-based learning and training procedures. Micro-economic empirical evidence suggests that there is no significant correlation between technological change and wages of human capital (DiNardo \& Pischke, 1997). This is due to increases in the number of information workers engaging in information services and products distribution (Lyon, 1988). As new ideas are repeatedly developed through the economic production process in metropolitan regions (Jacobs, 1969), the importance of human capital is reflected by the presence of ideas among workers. These facilitate and support economic growth (Lucas, 1988).

This importance attributed to human capital can be clearly illustrated by Nobel laureate Gary Becker: "The continuing growth in per capita incomes of many countries during the nineteenth and twentieth centuries is partly due to the expansion of scientific and technical knowledge that raises the productivity of labor and other inputs in production. The increasing reliance of industry on sophisticated knowledge greatly enhances the value of education, technical schooling, on-the-job training, and other human capital" (Becker, 1992). It therefore follows that human capital forms a basis for innovation. In this paper, the author focused on workers engaged in research 
and development as human capital, which in turn amounts to the basis for innovation. This industry approach is one of many methods to ascertain the innovation capacity of a region.

\section{OBJECTIVES}

From the preceding discussion, we have established that knowledge work is complex but can be defined as innovation. A region's innovation capacity is therefore, its ability to create knowledge or innovate. Human capital is an integral component of the knowledge economy because it constitutes a foundation for knowledge to be created.

Under these definitions, the aim of this exploratory research is to test the influence of innovation on economic performance at a regional level of analysis. The two objectives in this study are:

- To compare the innovation capacity among metropolitan regions in the U.S

- To explain the economic impact of innovation capacity in the U.S

A state may consist of several cities. Among which, some may be growing considerably faster than others. For instance, Philadelphia and Pittsburgh are the two key cities in the state of Pennsylvania, but their economic performances are very different from Altoona, another city in the same state. Also, cities may have an economic influence on their surrounding areas.

Metropolitan regions may not necessarily be highly urbanized regions. Based on the metropolitan statistical regions (MSAs), as per defined by the Bureau of Labor Statistics in the U.S., every city belongs to a larger area of analysis called an MSA. Highly urbanized metropolitan regions provide a higher, and necessarily faster, rate of human interactions (Glaeser, 1999). Hence, metropolitan areas or regions are used instead of cities to capture this phenomenon. Metropolitan Statistical Areas (MSAs) are used for this purpose and are universally defined by the U.S. Bureau of Labor Statistics, Census Bureau, and other government departments for analytical and policymaking purposes.

\section{OPERATIONALIZATION}

The following table summarizes the operationalization of the key variables: innovation capacity and economic performance. Following the literature review, innovation is based on ideas. In the knowledge economy is dependent on human capital and is characterized by ideas and creativity. Therefore, in this study, a measure 
of the location quotient of $\mathrm{R} \& \mathrm{D}$ workers is used to reflect the innovation capacity of a region.

Table 1 Description of Variables

\begin{tabular}{|c|c|c|}
\hline Variable & Operationalization & Description \\
\hline 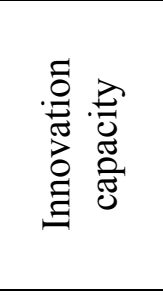 & $\begin{array}{l}\text { Economic base of } \\
\text { R\&D industry }\end{array}$ & $\begin{array}{l}\text { The employment location quotient (LQ) of an industry illustrates } \\
\text { the relative employment concentration of that industry in the } \\
\text { regional compared to that of the U.S. } \\
\text { An LQ measure captures the concentration of the industry with } \\
\text { respect to the U.S., and hence reflects the regional innovation } \\
\text { capacity created by workers. }\end{array}$ \\
\hline \multirow{2}{*}{ 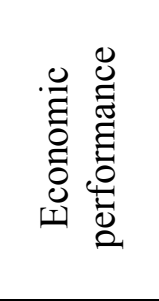 } & $\begin{array}{c}\text { Total annual } \\
\text { output }\end{array}$ & $\begin{array}{l}\text { This refers to the total GDP of all industries in a region in a given } \\
\text { year. } \\
\text { This is a direct measure of a region's economic output. }\end{array}$ \\
\hline & Total productivity & $\begin{array}{l}\text { For purposes of this research, this is computed by the total output } \\
\text { per worker in a region. } \\
\text { This measure suggests the efficiency of a region. }\end{array}$ \\
\hline
\end{tabular}

\section{Innovation Capacity}

The innovation capacity of a region (i.e. MSA) is its ability to create knowledge. Since a key component for creating knowledge is research and development (R\&D), it may be possible to look at R\&D industries as an operationalization for innovation capacity. In this study, annual location quotients (LQ) of the whole R\&D industry in a region were used to measure its innovation capacity. Location quotients are calculated as a measure of a region's economic base in a specific industry, with respect to a larger context (Wong, Yeo, \& DeVol, 2006). An industry in a region that has a concentration higher than the U.S. (i.e. $L Q \geq 1.0$ ) can be said to have a stronger base than the U.S. Of note, other indicators such as advanced degrees granted, number of patents awarded or licenses executed by region are also useful in accessing the regional innovation capacity, this paper looks at innovation created by the workforce. The use of these other indicators is discussed in the concluding section of this paper.

The definition of the R\&D industry will follow the definition laid out by the North American Industry Classification System (NAICS). This is a universal definition used by the U.S. Bureau of Labor Statistics, Bureau of Economic Analysis, and other government bodies. Based on the latest 2007 NAICS codes, the R\&D industry is defined as code number 5417, or Scientific Research and Development Services. It includes industries "engaged in conducting original investigation undertaken on a systematic basis to gain new knowledge (research) and/or the 
application of research findings or other scientific knowledge for the creation of new or significantly improved products or processes (experimental development)," (U.S. Census Bureau, 2004).

\section{Economic Performance}

The economic performance of a region can be operationalized in many ways. Quantitatively, a strong economy is one that has a high Gross Domestic Output (GDP) and high worker efficiency.

The GDP of a region can be directly measured using data at the MSA level. This will show the real total annual output of that region. In terms of productivity, a measure of total output per worker at the MSA level, was used as an indicator to indicate the level of efficiency, and hence productivity.

\section{METHOD}

Using data from Moody's Economy.com, a database comprising data from official sources, there are 378 metropolitan regions in the U.S. Data for all variables were collected for the years 1987 to 2007 inclusive, making a total sample size of 7,938 cases $(n=7,938)$. Location quotients were computed for the R\&D industry for each MSA using the following formula.

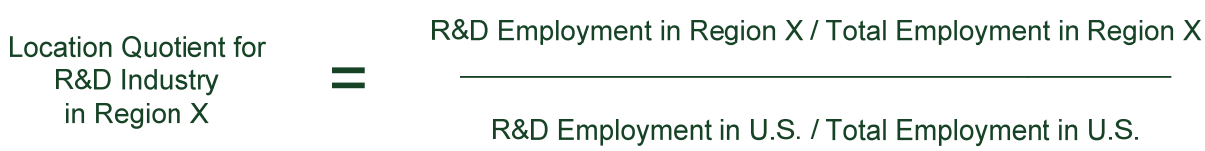

The number of workers in the R\&D industry for each MSA was used along with its total employment. Since the LQs for each MSA were computed against the U.S. as a benchmark, the corresponding R\&D industry employment and total employment in the U.S. were also obtained. The data were compiled and correlated to show their relationships. In addition, regressions were run to test whether a region's innovation capacity has a significant impact on its real output and productivity. The following section shows a summary of descriptive findings, followed by the correlations, and finally a discussion of the findings. 


\section{FINDINGS AND DISCUSSION}

Consolidating annual data on innovation capacity, industry output, and productivity from 378 metropolitan regions in the U.S. from 1988 to 2007, the sample size comprised 7,938 occurrences. Figure 1 shows the indexed growth in all three variables from 1988 to 2007.

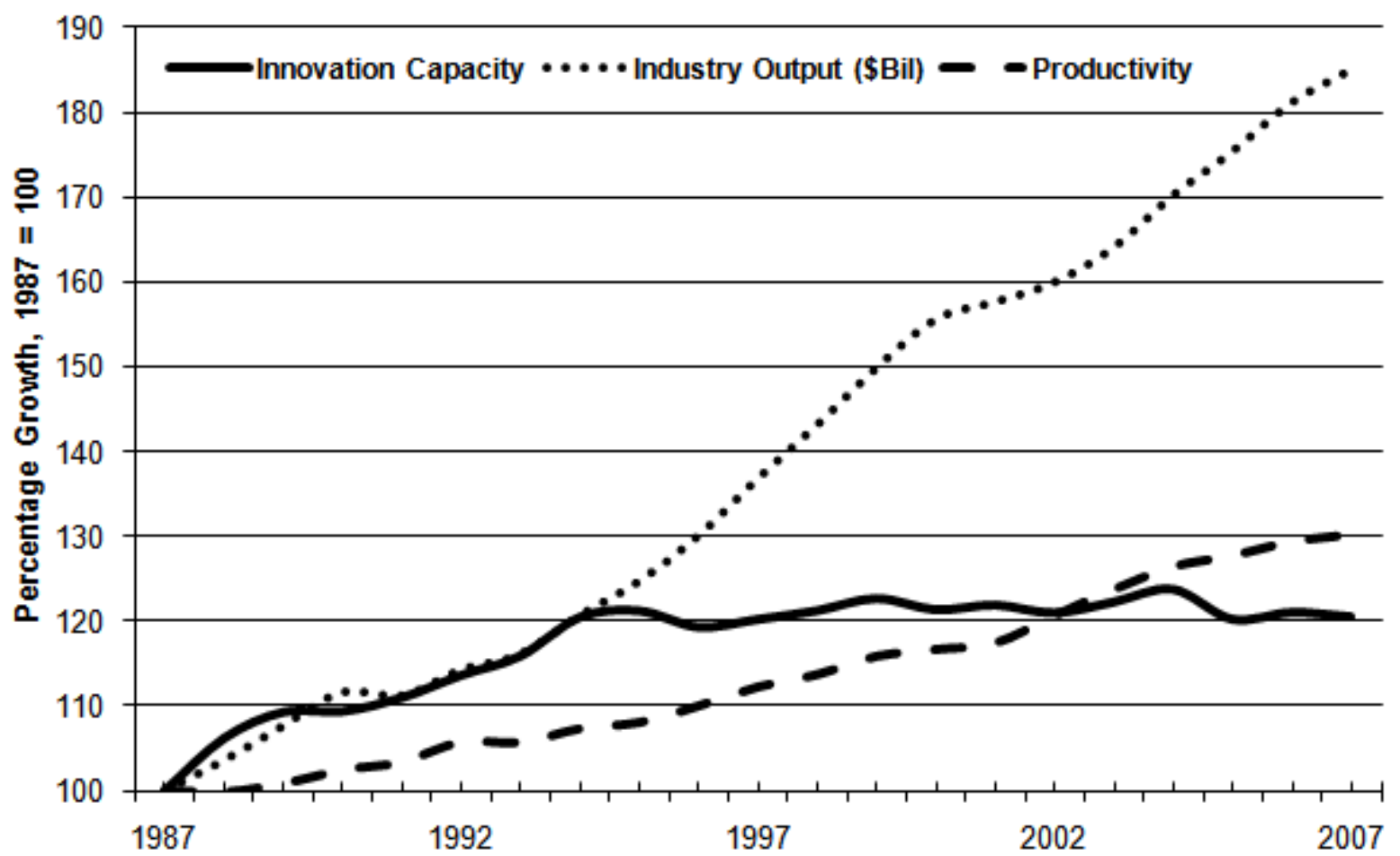

Figure 1 Innovation and Economic Growth, Indexed Growth, 1987 to 2007

As shown, industry output increased most substantially. Productivity also increased at a higher rate than innovation capacity (operationalized by the employment location quotients of the $R \& D$ industry). Although the annual average innovation capacities of U.S. metropolitan regions only experienced a marginal increase for the period, there was a corresponding but larger increase in average annual industry output and average annual productivity. Although average industry output increased steadily throughout the period, after 2000, it can be seen that the level of productivity was increasing at a slightly faster rate than before. This can be explained by the advent of information technologies after the dot com era.

The period of 20 years was divided into two eras: pre-dot com (1988-1997), and post-dot com eras (1998-2007). Independent sample t-tests were executed to ascertain the mean differences in all three variables between these eras. Table 2 illustrates these results. 
Table 2 Two-sample Mean Differences

\begin{tabular}{c|cc|cc|cc}
\hline & \multicolumn{2}{|c|}{ Innovation Capacity } & \multicolumn{2}{c|}{ Industry Output } & \multicolumn{2}{c}{ Productivity } \\
& $1998-2007$ & $1988-1997$ & $1998-2007$ & $1988-1997$ & $1998-2007$ & $1988-1997$ \\
\hline Mean & 0.757 & 0.706 & 23693.42 & 16749.71 & 72.512 & 62.359 \\
Observations & 3780 & 4158 & 3780 & 4158 & 3780 & 4158 \\
df & 7928 & & 6814 & & 7556 & \\
t-statistic & 1.742 & & $7.311^{*}$ & & $42.623^{*}$ & \\
\hline
\end{tabular}

* significant at $99 \%$ confidence interval

At a 95 percent confidence interval, the two-tailed t-statistics showed that there was no significant difference in the mean innovation capacities among U.S. metropolitan regions in both eras $(p=.08)$. However, in terms of industry output and productivity, the t-tests showed significant differences between the two eras.

These findings correspond to the descriptive findings mentioned earlier in this section. Although the innovation capacities of U.S. regions increased only marginally, the corresponding industry outputs and productivity levels increased significantly with the advent of information technologies. The following analyses will illustrate the impact of regional innovation capacity on industry output and productivity.

\section{Analysis}

Correlation tests were run in the pre- and post-dot come eras to ascertain the relationships among the three variables. Table 3 shows the level of correlations. In both cases, correlations were small. However, there was a substantial increase in the magnitudes in the post-dot com era. The correlation between innovation capacity and industry output increased from .13 to .16. A sharper increase was shown between innovation capacity and productivity, which increased from .15 to .26. Although the magnitudes were small, these findings suggest that the importance of a region's innovation capacity is becoming more relevant in the post-dot com era. This can be explained with the advent of the knowledge economy, whereby knowledge (or innovation) is playing an increasingly important role in regional economic growth.

Table 3 Results of Correlations

\begin{tabular}{lcc|cc|cc}
\hline & \multicolumn{2}{c|}{ Productivity } & \multicolumn{2}{c|}{ Industry Output } & Innovation Capacity \\
& $1988-1997$ & $1998-2007$ & $1988-1997$ & $1998-2007$ & $1988-1997$ & $1998-2007$ \\
\hline Productivity & 1.00 & 1.00 & & & & \\
Industry Output & 0.29 & 0.42 & 1.00 & 1.00 & & \\
Innovation Capacity & 0.15 & 0.26 & 0.13 & 0.16 & 1.00 & 1.00 \\
\hline
\end{tabular}


To further understand the impact of innovation capacity on a region's economic performance, regression analyses were run on all variables for both eras. Table 4 highlights the key findings from the analyses.

From the findings, prior to the dot com era, innovation capacity did not play a major role in determining industry output and productivity. With R2 statistics of .01, industry output and productivity were likely to have been determined by other factors. However, in the post-dot com era, the R2 statistics between innovation and the two variables were also small (.03 for industry output and .07 for productivity). Nonetheless, innovation capacity can be argued to be playing a more important role in predicting a region's industry output and productivity in the post-dot com era, whereby knowledge has become more valued as an input to the economy.

Table 4 Regression Results

\begin{tabular}{lcc}
\hline Regression Statistics on Industry Output & $1998-2007$ & $1988-1997$ \\
\hline Multiple R & 0.16 & 0.12 \\
R Square & 0.03 & 0.01 \\
Adjusted R Square & 0.03 & 0.01 \\
Observations & 3780 & 3780 \\
\hline Regression Statistics on Productivity & $1998-2007$ & $1988-1997$ \\
\hline Multiple R & 0.26 & 0.12 \\
R Square & 0.07 & 0.01 \\
Adjusted R Square & 0.07 & 0.01 \\
Observations & 3780 & 3780 \\
\hline
\end{tabular}

\section{Discussion}

The analysis suggests that with the advent of the knowledge economy, changes are surfacing in a region's industry structure. Innovation capacity appears to be a stronger driving force of economic growth after the dot com era, where information technologies and innovation began to overtake physical infrastructure inputs as drivers of growth. However, the statistical relationships were not obvious. This suggests that there may be other factors that are important.

Along with the significant increase in the average innovation capacity in the U.S. after 1998, average productivity and average industry output showed significant increases as well. The small magnitude of increase could be due to the concentration of innovation capacity in key metropolitan regions in the U.S., such as San Jose and Boston, rather than the central states such as Kansas, and Utah. Some regions are faster in their knowledge revolution than others. As a result, computing average 
innovation capacities, industry outputs, and productivity levels across the U.S. may not be a good method to ascertain the real impact of innovation capacity. In addition, using location quotients as the only measure may not be sufficient to capture a region's innovation capacity because it only reflects the human capital driven aspect of innovation.

The correlations among innovation capacity and industry output and productivity were stronger after 1998. These signify the higher importance of innovation as economies transit towards the knowledge economy. However, the magnitudes were also small. From the regressions, innovation capacity became a slightly better predictor of industry output and productivity after 1998. Figure 2 summarizes these relationships.

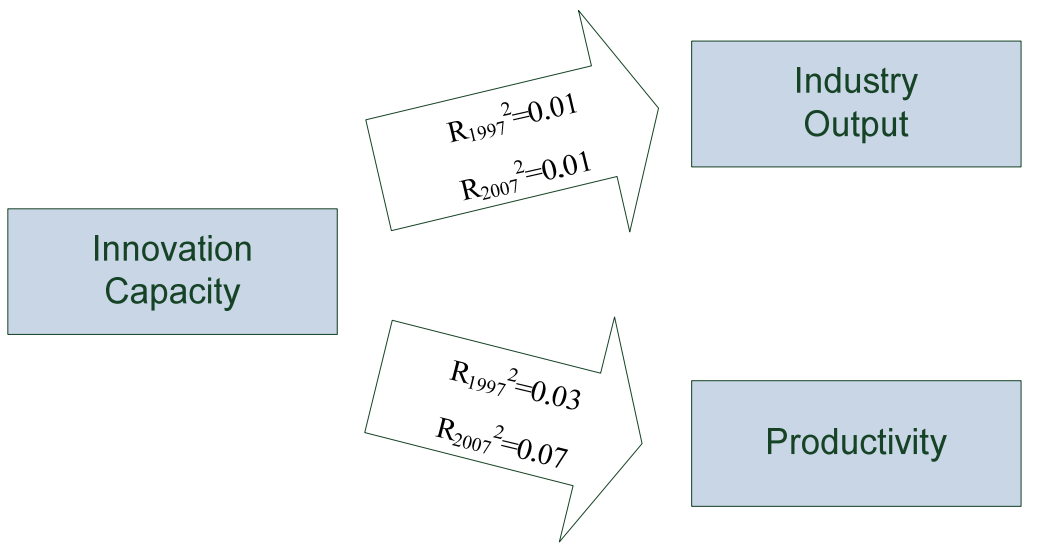

Figure 2 Summary of results

An explanation for the marginal increase in the model's strength in predicting the relationships is the presence of other factors. Scholarly work has suggested that contextual forces influence the impact of technologies and technological innovation on the economy. For example, even though Boston's Route 128 and California's Silicon Valley have similar agricultural roots and technology availability, these two regions have different industrial systems.

In Boston, Route 128 was characterized by independent and self-sufficient businesses. However, this quality facilitated its relative decline compared to Silicon Valley, which has a cooperative, but decentralized industrial system. This system played a key role in its sustained economic growth as businesses formed formal and informal social networks. These networks among businesses, universities and institutions are similar to clusters whereby production is organized around their social and economic relationships (Saxenian, 1996). Hence, Silicon Valley's social context allowed its technological innovation to play a stronger role in triggering its economic 
growth. The following sections will review literature in this vein to argue that a contextual approach is needed to develop a better understanding of how regional innovation capacity can drive growth in the knowledge economy.

\section{A Contextual Approach to the Knowledge Economy}

According to Yeo (2009), studies on the knowledge economy can adopt a social approach, whereby researchers examine the contextual meanings associated with markets and how these meanings influence the exchange of goods and services in an economy (Zelizer, 1988; Swedberg, 1991). Using this social approach, contextual factors involving public policies and culture for example, become important in shaping an economy. Since the knowledge economy where ideas and creativity are direct driving forces, these social factors play more important roles in influencing economic growth.

This approach stands in contrast to looking at information technologies per se, such as computer penetration. Kling argued that information technologies (IT) do not exist in social or technological isolation (Kling, 2000). Their interactions with institutional and cultural contexts play an important role in understanding facets of their use and the effects of these technologies. A lack of understanding of social and organizational contexts and the lack of understanding of users' behavior and needs will mean that IT applications have the same meaning for all users and provide the same consequence across all cases (Kling, 2003). However, the same technologies have different impact in different contexts.

Rosegrant and Lampe (1992) noted that policies and governments play important roles that affect the contexts within which innovation occurs (Rosegrant \& Lampe, 1992). The prominent discourses in this interplay of political institutions and knowledge involve university research contracts, laboratories, and various research and development contracts. Yeo's (2009) research showed that the adoption of technologies in different contexts may yield different results. His interpretive case studies of Ennis, a town in Ireland, San Joaquin Valley, a region in California, and Singapore showed that social contexts play important roles in determining the impact of technologies on the economy.

According to Basu (2003), the development of a knowledge economy must be supported by the national culture, because it is closely related to the success or failure of the economy. As an example, Japan's successful economy was shaped by its traditional values - cooperation, lack of self-achieving drives, tradition, stability, and shared knowledge. Its economic strength is based on stability rather than quick results. 
In addition, the Japanese philosophy emphasizes knowledge and the learning process. Hence, they follow lessons learned from best practices and adapt them to their own economic contexts (Basu, 2003). These findings show that social contexts play important roles in shaping a knowledge economy.

\section{Fitting the Context to Economic Growth}

In conclusion, contextual forces are important considerations in attempting to understand the impact of innovation capacity on economic growth. However, these social factors are varied and can fall within a broad spectrum. Yeo's (2009) research identified broad themes that can help frame the context for this purpose. These factors include regional social characteristics such as learning attitudes and social networks that influence economic growth. Although the LQ of R\&D workers by itself, reflects the innovation capacity of a region, social characteristics may affect how the industry influences the economy. This definition allows researchers to have a clear understanding of innovation at the macro level. However, it does not explain the roots of innovation or the means by which innovation can be achieved. As discussed earlier, the cases of California's Silicon Valley and Boston's route 128 show that social factors play important roles in shaping an industry and hence the economy (Saxenian, 1996).

This study shows an exploratory method to attempt to ascertain the economic impact of regional innovation capacity. Since the knowledge economy is characterized by ideas and creativity, it is important to show how innovation capacities can facilitate regional economic growth. Future research may adopt the same method but use more detailed measures of innovation capacity, including measures of advanced degrees granted, patents awarded, and licenses executed. In addition, the number of startups and R\&D funding can also be used to boost the measure of regional innovation capacity.

Also, future studies can also adopt a qualitative approach to identify regionspecific factors that can be quantified for regression analyses. As argued, different regions in the U.S. are at different stages of economic development. Therefore, studying region-specific experiences may be more important at this point than aggregating these economic performances to the national level for analysis. In this vein, high-growth regions can be benchmarked to low growth ones to ascertain regional differences. In this way, researchers can develop stronger models to explain how innovation capacities can drive growth in the intangible and value-oriented knowledge economy. 


\section{REFERENCES}

Basu, D. (2003). Globalization, culture, and the future of India. In F. J. Ritcher \& P. Banerjee (Eds.), The knowledge economy in India (pp. 260-277). New York: Palgrave Macmillan.

Becker, G. (1992). Human capital and the economy. Proceedings of the American Philosophical Society, 135(1), 85-92.

Bell, D. (1973). The coming of the post-industrial society. A venture in social forecasting. New York: Basic Books.

Block, F. (1990). Postindustrial possibilities: A critique of economy discourse. Berkeley: University of California Press.

Desrochers, P. (2001). Local diversity, human creativity, and technological innovation. Growth and Change, 32(3), 381-383.

DeVol, R. (2002). State technology and science index. Comparing and contrasting California. Santa Monica, USA: Milken Institute.

Dillon, T. A., Lee, R., \& Matheson, D. (2005). Value innovation: Passport to Wealth Creation. Research. Technology Management. (March-April 2005), 22-36.

DiNardo, J., \& Pischke, J. S. (1997). The returns of computer-use re-visited: Have pencils changed the wage structure too? Quarterly Journal of Economics, 112(1), 291-303.

Ernst and Young (1999). The Knowledge Economy. A submission to the New Zealand government by the Minister for Information Technology's IT Advisory Group. New Zealand: Ministry of Economic Development.

Florida, R. (2002). The rise of the creative class - And how it's transforming work, leisure, community and everyday life. New York, NY: Basic Books.

Gault, F. (2005). Measuring knowledge and its economic effects: The role of official statistics. In B. Kahin \& D. Dominique (Eds.) Measuring knowledge and its economic effects: Advancing knowledge and the knowledge economy. (pp. 27-42). U.S.A.: National Academies.

Glaeser, E. (1999). Learning in cities. Journal of Urban Economics, 46(2), 254-277.

Hulten, C. R. (2001). Total factor productivity: A short biography. In C. R. Hulten, E. R. Dean, \& M. J. Harper (Eds.), New Developments in Productivity Analysis (National Bureau of Economic Research Studies in Income and Wealth) (pp. 154). Chicago: University of Chicago Press.

Jacobs, J. (1969). The economy of cities. New York: Vintage.

Kim, W. C., \& Mauborgne, R. E. (1999). Strategy, value innovation, and the 
knowledge economy. Sloan Management Review, Spring 1999(40), 51-54.

Kling, R. (2000). Social informatics: New perspective on Social Research about Information and Communication Technologies. Prometheus: Critical Studies in Innovation, 18(3), 245-264.

Kling, R. (2003). Social Informatics. Encyclopedia of Library and Information Science: Second Edition, 2656-2661.

Lucas, R. (1988). On the mechanics of economic development. Journal of Monetary Economics, 22(1), 3-42.

Lyon, D. (1988). The information society: Issues and illusions. Cambridge, UK: Polity Press.

Mosco, V. (1989). The Pay-Per Society: Computers and Communication in the Information Age. Toronto, Ontario: Garamond Press.

National Science Foundation. (2007). Advancing measures of innovation. Knowledge flows, business metrics, and measurement strategies (Report No. NSF 07-306). US: National Science Foundation.

Powell, W. W., \& Snellman, K. (2004). The knowledge economy. Annual Review of Sociology, 30, 199-220.

Romer, P. M. (1986). Increasing Returns and Long-run Growth. Journal of Political Economy, 94(5), 1002-1037.

Romer, P. M. (1990). Endogenous technological change. Journal of Political Economy, 98(5), 71-102.

Rosegrant, S., \& Lampe, D. (1992). Route 128. Lessons from Boston's High-Tech Community. New York, NY: Basic Books.

Saxenian, A. (1996). Regional advantage: Culture and competition in Silicon Valley and Route 128. Cambridge, MA: Harvard University Press.

Swedberg, R. (1991). Major traditions of economic sociology. Annual Review of Sociology, 17, 251-276.

U.S. Census Bureau. (2004). Industry statistics sampler: NAICS 5417. Retrieved November 23, 2004, from http://www.census.gov/epcd/ec97/industry/E5417.htm

U.S. Congress, Office of Technology Assessment. (1995). Innovation and commercialization of emerging technologies. Office of Technology Assessment. OTA-BP-ITC-165 Washington, DC: U.S. Government Printing Office.

Ullman, E. L. (1958). Regional Development and the Geography of Concentration. Papers in Regional Science, 4(1), 179-198.

World Bank (1999). World Development Report 1998/99: Knowledge for Development. Washington DC: World Bank. 
Wong, P., Yeo, B., \& DeVol, R. (2006). Pittsburgh technology strategy: SWOT analysis. Santa Monica, USA: Milken Institute.

Yeo, B. (2009). Developing a Sustainable Knowledge Economy: The Influence of Contextual Factors. Germany: VDM Verlag Dr. Müller.

Zelizer, V. (1988). Beyond the polemics of the market: Establishing a theoretical and empirical agenda. Sociological Forum, 3, 614-634. 